\title{
FIXED POINT OF CONTINUOUS MAPPINGS DEFINED ON AN ARBITRARY INTERVAL
}

\author{
OSMAN ALAGOZ, BIROL GUNDUZ, AND SEZGIN AKBULUT \\ Dedicated to Birol Gunduz who is one of the co-authors and passed away on the 3rd of April, 2019.
}

Received 30 January, 2018

\begin{abstract}
In this work, we consider an iterative method given by Karaca and Yildirim [6] to approximate fixed point of continuous mappings defined on an arbitrary interval. Then, we give a necessary and sufficient condition for convergence theorem. We also compare the rate of convergence between the other iteration methods. Finally, we provide a numerical example which supports our theoretical results. Our findings improve corresponding results in the contemporary literature.
\end{abstract}

2010 Mathematics Subject Classification: 26A18; 47H10; 54C05

Keywords: continuous mapping, convergence theorem, fixed point

\section{INTRODUCTION AND PRELIMINARIES}

Let $E$ be a closed interval which is a subset of reel line and let $f: E \rightarrow E$ be a continuous function. Any $p \in E$ is called a fixed point of $f$ if $f(p)=p$. The set of all fixed points of $f$ is denoted by $F(f)$. It is known that any linear or non-linear equation $f(x)=0$ can be turned into a fixed point problem such as:

$$
g(x)=x
$$

where $g: E \rightarrow E$ is a contraction. In order to approximate fixed points of (1.1), Picard iteration can be applied. If $g$ does not satisfy the contractive condition, then some other iteration methods can be applied to obtain a solution of (1.1). Thus, a question appears. Which iteration method should be used for approximating the fixed points of (1.1)?

In 1953, W.R. Mann defined an iteration called Mann iteration [7] to approximate fixed point of a non-linear mapping as follows: a sequence $\left\{x_{n}\right\}$ defined by $x_{1} \in E$ and

$$
x_{n+1}=\left(1-\alpha_{n}\right) x_{n}+\alpha_{n} f\left(x_{n}\right)
$$


for all $n \geq 1$, where $\left\{\alpha_{n}\right\}$ is a sequence in [0,1]. In 1991, D. Borwein and J. Borwein [2] proved a convergence theorem for a continuous function by using the iteration (1.2).

In 1974, Ishikawa [4] introduced an iteration process as follows: a sequence $\left\{x_{n}\right\}$ defined by $x_{1} \in E$ and

$$
\begin{cases}y_{n} & =\left(1-\beta_{n}\right) x_{n}+\beta_{n} f\left(x_{n}\right) \\ x_{n+1} & =\left(1-\alpha_{n}\right) x_{n}+\alpha_{n} f\left(y_{n}\right)\end{cases}
$$

for all $n \geq 1$ where $\left\{\alpha_{n}\right\}$ and $\left\{\beta_{n}\right\}$ are sequences in [0,1]. In 2006, Qing and Qihou [11] proved a convergence theorem of the sequence generated by the iteration (1.3) for continuous function.

In 2000, Noor [8] defined the following iterative scheme by $x_{1} \in E$ and

$$
\begin{cases}z_{n} & =\left(1-\gamma_{n}\right) x_{n}+\gamma_{n} f\left(x_{n}\right) \\ y_{n} & =\left(1-\beta_{n}\right) x_{n}+\beta_{n} f\left(z_{n}\right) \\ x_{n+1} & =\left(1-\alpha_{n}\right) x_{n}+\alpha_{n} f\left(y_{n}\right)\end{cases}
$$

for all $n \geq 1$, where $\left\{\alpha_{n}\right\},\left\{\beta_{n}\right\}$ and $\left\{\gamma_{n}\right\}$ are sequences in $[0,1]$. Clearly the Mann and the Ishikawa iterations are special cases of the Noor iteration.

Recently, Phuengrattana and Suantai [9] introduced SP-iteration as follows: $x_{1} \in$ $E$ and

$$
\begin{cases}z_{n} & =\left(1-\gamma_{n}\right) x_{n}+\gamma_{n} f\left(x_{n}\right) \\ y_{n} & =\left(1-\beta_{n}\right) z_{n}+\beta_{n} f\left(z_{n}\right) \\ x_{n+1} & =\left(1-\alpha_{n}\right) y_{n}+\alpha_{n} f\left(y_{n}\right)\end{cases}
$$

for all $n \geq 1$, where $\left\{\alpha_{n}\right\},\left\{\beta_{n}\right\}$ and $\left\{\gamma_{n}\right\}$ are sequences in $[0,1]$. They proved a convergence theorem of the iteration (1.5) for continuous functions defined on an arbitrary interval in the real line.

In 2013, Kadioglu and Yildirim [5] defined the following iteration process: $x_{1} \in E$ and

$$
\begin{cases}z_{n} & =\left(1-a_{n}\right) x_{n}+a_{n} f\left(x_{n}\right) \\ y_{n} & =\left(1-b_{n}-c_{n}\right) x_{n}+b_{n} f\left(z_{n}\right)+c_{n} f\left(x_{n}\right) \\ x_{n+1} & =\left(1-\alpha_{n}-\beta_{n}\right) x_{n}+\alpha_{n} f\left(y_{n}\right)+\beta_{n} f\left(z_{n}\right)\end{cases}
$$

for all $n \geq 1$, where $\left\{\alpha_{n}\right\},\left\{\beta_{n}\right\},\left\{a_{n}\right\},\left\{b_{n}\right\}$ and $\left\{c_{n}\right\}$ are sequences in $[0,1]$. They also showed that the iteration (1.6) converges to a fixed point of $f$. Moreover, they showed that the iteration of (1.6) is better than Mann, Ishikawa and Noor iteration processes in the sense of Rhoades [12]. In 2006, Cholamjiak and Baiya [3] proposed a new three-step iteration process for solving a fixed point problem for continuous 
functions on an arbitrary interval in the real line as follows: $p_{1} \in E$ and

$$
\begin{cases}r_{n} & =\left(1-a_{n}\right) p_{n}+a_{n} f\left(p_{n}\right) \\ q_{n} & =\left(1-b_{n}-c_{n}\right) r_{n}+b_{n} f\left(r_{n}\right)+c_{n} f\left(p_{n}\right) \\ p_{n+1} & =\left(1-\alpha_{n}-\beta_{n}\right) q_{n}+\alpha_{n} f\left(q_{n}\right)+\beta_{n} f\left(r_{n}\right)\end{cases}
$$

where $\left\{\alpha_{n}\right\},\left\{\beta_{n}\right\},\left\{a_{n}\right\},\left\{b_{n}\right\}$ and $\left\{c_{n}\right\}$ are sequences in $[0,1)$ with $0 \leq b_{n}+c_{n}<1$ and $0 \leq \alpha_{n}+\beta_{n}<1$. They also showed that the iteration (1.7) is better than the iteration (1.6) in the sense of Rhoades [12].

On the other hand in 2014, Karaca and Yildirim [6] defined a new iteration as fallows: Let $u_{1} \in E$ and the sequence $\left\{u_{n}\right\}$ be defined by

$$
\begin{cases}w_{n} & =\left(1-a_{n}\right) u_{n}+a_{n} f\left(u_{n}\right) \\ v_{n} & =\left(1-b_{n}\right) w_{n}+b_{n} f\left(w_{n}\right) \\ u_{n+1} & =f\left(v_{n}\right)\end{cases}
$$

where $\left\{a_{n}\right\}$ and $\left\{b_{n}\right\}$ are sequence in $(0,1)$. They showed that the iteration (1.8) process is faster than all of Picard [10], Mann [7], Ishikawa [4] and Agarwal et al. [1] processes. They also proved a convergence theorem for nonexpansive mappings in Banach spaces.

In this paper we prove some convergence theorems by using the (1.8) iteration for continuous function defined on an arbitrary closed interval in the real line. Secondly, we compare the rate of convergence of (1.7) iteration and (1.8) iteration in the sense of Rhoades [12].

\section{CONVERGENCE THEOREMS}

In this section, we propose convergence theorem for the iteration process defined by (1.8) for continuous functions on an arbitrary interval.

Theorem 1. Let $E$ be a closed interval in the real line and let $f: E \rightarrow E$ be a continuous mapping. For $x_{1} \in E$, let the iteration $\left\{u_{n}\right\}$ be defined by (1.8), where $\left\{\alpha_{n}\right\}$ and $\left\{\beta_{n}\right\}$ are sequences in $[0,1]$ such that $\lim _{n \rightarrow \infty} \alpha_{n}=0, \lim _{n \rightarrow \infty} \beta_{n}=0$ and $\lim _{n \rightarrow \infty}\left|f\left(v_{n}\right)-v_{n}\right|=0$. Then $\left\{u_{n}\right\}$ is bounded if and only if $\left\{u_{n}\right\}$ converges to a fixed point of $f$.

Proof. If $\left\{u_{n}\right\}$ converges to a fixed point of $f$ then it is obvious that $\left\{u_{n}\right\}$ is bounded. Now, assume that $\left\{u_{n}\right\}$ is bounded. Our goal is to show that $\left\{u_{n}\right\}$ is convergent. Assume to get a contradiction that it is not. Then there exist $a, b \in \mathbb{R}$, $a=\liminf _{n \rightarrow \infty} u_{n}, b=\limsup _{n \rightarrow \infty} u_{n}$ and $a<b$. First, we show that if $a<m<b$, then $f(m)=m$. Suppose that $f(m) \neq m$ Then, without loss of generality, we suppose that $f(m)-m>0$. Since $f$ is a continuous mapping, there exists $\delta \in(0, b-a)$ such that

$$
f(x)-x>0 \text { for }|x-m| \leq \delta .
$$


By the hypothesis of $\left\{u_{n}\right\}$, we have $\left\{u_{n}\right\}$ belongs to a bounded closed interval. The continuity of $f$ implies that $\left\{f\left(u_{n}\right)\right\}$ belongs to another bounded closed interval. So, $\left\{f\left(u_{n}\right)\right\}$ is bounded and since

$$
w_{n}=\left(1-\beta_{n}\right) u_{n}+\beta_{n} f\left(u_{n}\right)
$$

we get that $\left\{w_{n}\right\}$ is bounded and so, $\left\{f\left(w_{n}\right)\right\}$ is bounded. Similarly, since

$$
v_{n}=\left(1-\alpha_{n}\right) w_{n}+\alpha_{n} f\left(w_{n}\right),
$$

we have $\left\{v_{n}\right\}$ and $\left\{f\left(v_{n}\right)\right\}$ are bounded. It follows by (1.8) that

$$
\begin{aligned}
u_{n+1}-u_{n} & =f\left(v_{n}\right)-v_{n}+\alpha_{n}\left(f\left(w_{n}\right)-w_{n}\right)+\beta_{n}\left(f\left(u_{n}\right)-u_{n}\right), \\
v_{n}-u_{n} & =\beta_{n}\left(f\left(u_{n}\right)-u_{n}\right)+\alpha_{n}\left(f\left(w_{n}\right)-w_{n}\right), \\
w_{n}-u_{n} & =\beta_{n}\left(f\left(u_{n}\right)-u_{n}\right) .
\end{aligned}
$$

By the assumption of the theorem (1), we get $\left|u_{n+1}-u_{n}\right| \rightarrow 0,\left|v_{n}-u_{n}\right| \rightarrow 0$ and $\left|w_{n}-u_{n}\right| \rightarrow 0$. Thus, there exists $N$ such that

$$
\left|u_{n+1}-u_{n}\right|<\frac{\delta}{3}, \quad\left|v_{n}-u_{n}\right|<\frac{\delta}{3}, \quad\left|w_{n}-u_{n}\right|<\frac{\delta}{3}
$$

for all $n>\mathbb{N}$. Since $b=\limsup \operatorname{sum}_{n \rightarrow \infty} u_{n}>m$, there exists $k_{1}>\mathbb{N}$ such that $u_{n_{k_{1}}}>$ $m$. Let $k=n_{k_{1}}$, then $u_{k}>m$. For $u_{k}$, there exist only two cases;

Case 1: $u_{k} \geq m+\frac{\delta}{3}$, then by (2.2) we have $u_{k+1}-u_{k}>-\frac{\delta}{3}$, then $u_{k+1}>$ $u_{k}-\frac{\delta}{3} \geq m$, so $u_{k+1}>m$

Case 2: $m<u_{k}<m+\frac{\delta}{3}$, then by (2.2), we have $m-\frac{\delta}{3}<v_{k}<m+\frac{2 \delta}{3}$ and $m-\frac{\delta}{3}<w_{k}<m+\frac{2 \delta}{3}$. So, we have $\left|u_{k}-m\right|<\frac{\delta}{3},\left|v_{k}-m\right|<\frac{2 \delta}{3}<\delta$ and $\left|w_{k}-m\right|<$ $\frac{2 \delta}{3}<\delta$ Using (2.1) we get

$$
f\left(u_{k}\right)-u_{k}>0, \quad f\left(v_{k}\right)-v_{k}>0, \quad f\left(w_{k}\right)-w_{k}>0
$$

By iteration (1.8), we have

$$
u_{k+1}=u_{k}+f\left(v_{k}\right)-v_{k}+\alpha_{k}\left(f\left(w_{k}\right)-w_{k}\right)+\beta_{k}\left(f\left(x_{k}\right)-x_{k}\right)
$$

By Case 1 and Case 2, we can conclude that $u_{k+1}>m$. By using the above argument, we obtain $u_{k+2}>m, u_{k+3}>m, u_{k+4}>m \ldots$

Thus, we get $u_{n}>m$ for all $n=k=n_{k_{1}}$. So, $a=\liminf _{n \rightarrow \infty} u_{n} \geq m$ which is a contradiction with $a<m$. Thus, $f(m)=m$.

For the sequence $\left\{u_{n}\right\}$, we consider the following two cases,

Case $1^{\prime}$ : There exists $u_{m}$ such that $a<u_{m}<b$. Then, $f\left(u_{m}\right)=u_{m}$. Thus,

$$
\begin{aligned}
w_{m} & =\left(1-\beta_{m}\right) u_{m}+\beta_{m} f\left(u_{m}\right)=u_{m}, \\
v_{m} & =\left(1-\alpha_{m}\right) u_{m}+\alpha_{m} f\left(w_{m}\right)=u_{m},
\end{aligned}
$$




$$
u_{m+1}=f\left(v_{m}\right)=f\left(u_{m}\right)=u_{m} .
$$

By induction, we obtain $u_{m}=u_{m+1}=u_{m+2}=u_{m+3}=\ldots$

So $u_{n} \rightarrow u_{m}$. This implies that $u_{m}=a$ and $u_{n} \rightarrow a$, which contradicts to our assumption.

Case $2^{\prime}$ : For all $n, u_{n} \leq a$ or $u_{n} \geq b$. Because $b-a>0$ and $\left|u_{n+1}-u_{n}\right| \rightarrow 0$, there exists $N_{0}$ such that $\left|u_{n+1}-u_{n}\right|<\frac{b-a}{3}$ for all $n>N_{0}$. This implies that either $u_{n} \leq a$ for all $n>N_{0}$ or $u_{n} \geq b$ for all $n>N_{0}$. If $u_{n} \leq a$ for $n>N_{0}$, then $b=\lim \sup _{n \rightarrow \infty} \leq a$, which is a contradiction with $a<b$. Hence, we have $\left\{u_{n}\right\}$ is convergent.

Finally, we show that $\left\{u_{n}\right\}$ converges to a fixed point of $f$. Let $u_{n} \rightarrow p$ and suppose that $f(p) \neq p$. By the continuity of $f$, we have $\left\{f\left(u_{n}\right)\right\}$ is bounded. From

$$
w_{n}=\left(1-\beta_{n}\right) u_{n}+\beta_{n} f\left(u_{n}\right)
$$

and $\beta_{n} \rightarrow 0$, we obtain $w_{n} \rightarrow p$. Similarly, by

$$
v_{n}=\left(1-\alpha_{n}\right) w_{n}+\alpha_{n} f\left(w_{n}\right)
$$

and $\alpha_{n} \rightarrow 0$, it follows that $v_{n} \rightarrow p$. Let $p_{k}=f\left(v_{k}\right)-u_{k}$. By the continuity of $f$, we have $\lim _{k \rightarrow \infty} p_{k}=\lim _{k \rightarrow \infty}\left(f\left(v_{k}\right)-u_{k}\right)=f(p)-p \neq 0$. Put $w=f(p)-p$. Then $w \neq 0$. By the iteration (1.8), we have

$$
u_{n+1}-u_{n}=f\left(v_{n}\right)-u_{n}
$$

it follows that

$$
u_{n}=u_{1}+\sum_{k=1}^{n-1} p_{k}
$$

By $p_{k} \rightarrow w \neq 0$, we have that $\sum_{k=1}^{\infty} p_{k}$ is divergent, which is a contradiction with $u_{n} \rightarrow p$. Thus, $f(p)=p$. That is, $\left\{u_{n}\right\}$ converges to a fixed point of $f$.

\section{RATE OF CONVERGENCE}

In this section, we give conclusions on the rate of convergence of the iteration (1.8) and the iteration (1.7). We use some useful definition and lemmas to do this.

Definition 1 ([12]). Let $E$ be a closed interval in the real line and let $f: E \rightarrow E$ be a continuous mapping. Suppose that $\left\{u_{n}\right\}$ and $\left\{x_{n}\right\}$ are two iterations which converge to a fixed point of $p$ of $f$. We say that $\left\{u_{n}\right\}$ is better than $\left\{x_{n}\right\}$ if

$$
\left|u_{n}-p\right| \leq\left|x_{n}-p\right|, \quad \forall n \geq 1
$$

Lemma 1 ( [3, Lemma 3.3]). Let $E$ be a closed interval in the real line and let $f: E \rightarrow E$ be a continuous and non-decreasing mapping. Let $\left\{\alpha_{n}\right\},\left\{\beta_{n}\right\},\left\{a_{n}\right\},\left\{b_{n}\right\}$ and $\left\{c_{n}\right\}$ be sequences in $[0,1)$ with $0 \leq b_{n}+c_{n}<1$ and $\alpha_{n}+\beta_{n}<1$. Let $\left\{p_{n}\right\}$ be defined by (1.7). Then the followings hold.

(1) If $f\left(p_{1}\right)<p_{1}$, then $f\left(p_{n}\right)<p_{n}$ for all $n \geq 1$ and $\left\{p_{n}\right\}$ is non-increasing 
(2) If $f\left(p_{1}\right)>p_{1}$, then $f\left(p_{n}\right)>p_{n}$ for all $n \geq 1$ and $\left\{u_{n}\right\}$ is non-decreasing

Lemma 2. Let $E$ be a closed interval in the real line and let $f: E \rightarrow E$ be a continuous and non-decreasing mapping. Let $\left\{\alpha_{n}\right\}$ and $\left\{\beta_{n}\right\}$ be sequences in $[0,1)$. Let $\left\{u_{n}\right\}$ be defined by (1.8). Then the followings hold.

(1) If $f\left(u_{1}\right)<u_{1}$, then $f\left(u_{n}\right)<u_{n}$ for all $n \geq 1$ and $\left\{u_{n}\right\}$ is non-increasing

(2) If $f\left(u_{1}\right)>u_{1}$, then $f\left(u_{n}\right)>u_{n}$ for all $n \geq 1$ and $\left\{u_{n}\right\}$ is non-decreasing

Proof. (1): Let $f\left(u_{1}\right)<u_{1}$. Then $f\left(u_{1}\right)<w_{1} \leq u_{1}$. Since $f$ is non-decreasing, we have $f\left(w_{1}\right) \leq f\left(u_{1}\right)<w_{1}$. On the other hand, we have $f\left(w_{1}\right)<v_{1} \leq w_{1}$. Since $f$ is non-decreasing we get $f\left(v_{1}\right) \leq f\left(w_{1}\right) \leq v_{1}$. It follows that $f\left(v_{1}\right)=u_{2} \leq v_{1}$, then $f\left(u_{2}\right) \leq f\left(v_{1}\right)=u_{2}$. Hence, we have $f\left(u_{2}\right)<u_{2}$. By induction, we conclude that $f\left(u_{n}\right)<u_{n}$ for all $n \geq 1$. This implies $f\left(u_{n}\right)<w_{n} \leq u_{n}$ for all $n \geq 1$. Since $f$ is non-decreasing, we have $f\left(w_{n}\right) \leq f\left(u_{n}\right)<w_{n} \leq u_{n}$ for all $n \geq 1$. Thus, $f\left(w_{n}\right)<$ $v_{n} \leq w_{n}$ for all $n \geq 1$. Then $f\left(v_{n}\right) \leq f\left(w_{n}\right) \leq u_{n}$ for all $n \geq 1$. Hence, we have $u_{n+1} \leq u_{n}$ for all $n \geq 1$, that is $\left\{u_{n}\right\}$ is non-increasing

(2): Following the line of (1), we show the desired result.

Lemma 3. Let $E$ be a closed interval in the real line and let $f: E \rightarrow E$ be a continuous and non-decreasing mapping. Let $\left\{a_{n}\right\},\left\{b_{n}\right\},\left\{c_{n}\right\},\left\{\alpha_{n}\right\}$ and $\left\{\beta_{n}\right\}$ be sequences in $[0,1)$. For $u_{1}=p_{1} \in E$, let $\left\{u_{n}\right\}$ and $\left\{p_{n}\right\}$ be the sequences defined by (1.8) and (1.7), respectively. Then, the following are satisfied:

(1) If $f\left(p_{1}\right)<p_{1}$ then $u_{n} \leq p_{n}$ for all $n \geq 1$.

(2) If $f\left(p_{1}\right)>p_{1}$ then $u_{n} \geq p_{n}$ for all $n \geq 1$.

Proof. (1): Let $f\left(p_{1}\right)<p_{1}$. Then $f\left(u_{1}\right)<u_{1}$ since $u_{1}=p_{1}$. From the iteration (1.8) we get, $f\left(u_{1}\right)<w_{1} \leq u_{1}$. Since $f$ is non-decreasing, we obtain $f\left(w_{1}\right) \leq$ $f\left(u_{1}\right)<w_{1} \leq u_{1}$. Hence, $f\left(w_{1}\right)<v_{1} \leq w_{1}$.

Using the iteration (1.7) and the iteration (1.8), we obtain the following estimation: $w_{1}-r_{1}=\left(1-a_{1}\right)\left(u_{1}-p_{1}\right)+a_{1}\left(f\left(u_{1}\right)-f\left(p_{1}\right)\right)=0$.

So, $w_{1}=r_{1}$, and also

$v_{1}-q_{1}=\left(1-b_{1}\right)\left(w_{1}-r_{1}\right)+b_{1}\left(f\left(w_{1}\right)-f\left(r_{1}\right)\right)+c_{1}\left(r_{1}-f\left(p_{1}\right)\right) \geq 0$.

Since $f$ is non-decreasing, we have $f\left(q_{1}\right) \leq f\left(v_{1}\right)$. On the other hand, if $f\left(p_{1}\right)<$ $p_{1}$. Then from the iteration (1.7), we get $f\left(p_{1}\right)<r_{1}<p_{1}$. Since $f$ is non-decreasing, we get $f\left(r_{1}\right)<f\left(p_{1}\right)<r_{1}$. By the iteration (1.7) we also conclude $f\left(r_{1}\right)<q_{1}<r_{1}$. Since $f$ is non-decreasing, we get $f\left(q_{1}\right)<f\left(r_{1}\right)<q_{1}$. Next, by using the above result which is $w_{1}=r_{1}$ in the inequality of $f\left(w_{1}\right)<v_{1}<w_{1}$, we get $f\left(r_{1}\right)<v_{1}<$ $r_{1}$. Since $f$ is non-decreasing, we get $f\left(v_{1}\right)<f\left(r_{1}\right)<v_{1}$ and so it follows that $f\left(v_{1}\right)<f\left(r_{1}\right)<q_{1}$. By using the above arguments, anyone can easily see that $u_{2}-p_{1}=f\left(v_{1}\right)-q_{1}+\alpha_{1}\left(q_{1}-f\left(q_{1}\right)\right)+\beta_{1}\left(q_{1}-f\left(r_{1}\right)\right) \leq 0$.

So, $u_{2} \leq p_{2}$. Assume that $u_{k} \leq p_{k}$. Thus $f\left(u_{k}\right) \leq f\left(p_{k}\right)$. From Lemma 1(i) and Lemma 2(i), we get $f\left(p_{k}\right)<p_{k}$ and $f\left(u_{k}\right)<u_{k}$. It follows that $f\left(u_{k}\right)<w_{k}<u_{k}$ and $f\left(w_{k}\right)<f\left(u_{k}\right)<w_{k}$. Hence, 
$w_{k}-r_{k}=\left(1-a_{k}\right)\left(u_{k}-p_{k}\right)+a_{k}\left(f\left(u_{k}\right)-f\left(p_{k}\right)\right) \leq 0$.

So, $w_{k} \leq r_{k}$. Since $f\left(w_{k}\right) \leq f\left(r_{k}\right)$,

$v_{k}-q_{k}=\left(1-b_{k}\right)\left(w_{k}-r_{k}\right)+b_{k}\left(f\left(w_{k}\right)-f\left(r_{k}\right)\right)+c_{k}\left(r_{k}-f\left(p_{k}\right)\right) \leq 0$.

So $v_{k} \leq q_{k}$, which yields $f\left(v_{k}\right) \leq f\left(q_{k}\right)$. This shows that

$u_{k+1}-p_{k+1}=f\left(v_{k}\right)-q_{k}+\alpha_{k}\left(q_{k}-f\left(q_{k}\right)\right)+\beta_{k}\left(q_{k}-f\left(r_{k}\right)\right) \leq 0$,

which gives, $u_{k+1} \leq w_{k+1}$. By induction, we conclude that $u_{n} \leq p_{n}$ for all $n \geq 1$.

(2): From Lemma 1(ii) and Lemma 2(ii) and the same proof as in (i), we can show that $u_{n} \geq p_{n}$ for all $n \geq 1$.

Theorem 2. Let $E$ be a closed interval in the real line and let $f: E \rightarrow E$ be a continuous and non-decreasing mapping such that $F(f)$ is non-empty and bounded. Let $\left\{a_{n}\right\},\left\{b_{n}\right\},\left\{c_{n}\right\},\left\{\alpha_{n}\right\}$ and $\left\{\beta_{n}\right\}$ be sequences in $[0,1)$. For $u_{1}=p_{1} \in E$, let $\left\{u_{n}\right\}$ and $\left\{p_{n}\right\}$ be the sequences defined by (1.8) and (1.7), respectivey, and converge to $p \in F(f)$. Then, the iteration (1.8) is better than (1.7).

Proof. Put $L=\inf \{p \in F: \quad p=f(p)\}$ and $U=\sup \{p \in E: \quad p=f(p)\}$. For $u_{1}$ there are three cases;

Case 1: $u_{1}=p_{1}>U$. By [9, Proposition 3.5], we get $f\left(u_{1}\right)<u_{1}$ and $f\left(p_{1}\right)<p_{1}$. Using Lemma 3(1), we get that $u_{n} \leq p_{n}$ for all $n \geq 1$.

Following the line of the proof of [9, Theorem 3.7], we have $U \leq u_{n}$ for all $n \geq 1$. Then we have $0 \leq u_{n}-p \leq p_{n}-p$, so $\left|u_{n}-p\right| \leq\left|x_{n}-p\right|$ for all $n \geq 1$. We can see that the iteration (1.8) is better than the iteration (1.7).

case 2: $u_{1}=p_{1}<U$. By [9, Proposition 3.5], we get $f\left(u_{1}\right)>u_{1}$ and $f\left(p_{1}\right)>p_{1}$. Using Lemma 3(2), we get that $u_{n} \geq p_{n}$ for all $n \geq 1$.

Following the line of the proof of [9, Theorem 3.7], we get $u_{n} \leq L$ for all $n \geq 1$. So, $\left|u_{n}-p\right| \leq\left|x_{n}-p\right|$ for all $n \geq 1$. We can see that the iteration (1.8) is better than the iteration (1.7).

Case 3: $L \leq u_{1}=p_{1} \leq U$. Suppose that $f\left(u_{1}\right) \neq u_{1}$. If $f\left(u_{1}\right)<u_{1}$, we have by Lemma $1(1)$ that $\left\{u_{n}\right\}$ is non-decreasing with limit $p$. By Lemma 3(1), we have $p \leq u_{n} \leq p_{n}$ for all $n \geq 1$. It follows that $\left|u_{n}-p\right| \leq\left|p_{n}-p\right|$ for all $n \geq 1$. Hence we have that the iteration (1.8) is better than the iteration (1.7). If $f\left(u_{1}\right)>u_{1}$, we have by Lemma 1(2) that $\left\{u_{n}\right\}$ is nondecreasing with limit $p$. By Lemma 3(2), we have $p \geq u_{n} \geq p_{n}$ for all $n \geq 1$. It follows that $\left|u_{n}-p\right| \leq\left|p_{n}-p\right|$ for all $n \geq 1$. Hence, we have that the iteration (1.8) is better than the iteration (1.7).

Now, we give a numerical example to compare the rates of convergence of the iteration (1.8) and the iteration (1.7).

Example 1. Let $f:[0,3] \rightarrow[0,3]$ be defined by $f(x)=\frac{x^{2}+6}{7}$. It is obvious that $f$ is continuous and non-decreasing with a fixed point $p=1$. Set the initial point $u_{1}=x_{1}=3.0$ and control sequences be defined by $\alpha_{n}=\beta_{n}=a_{n}=\frac{1}{n^{2}+1}, b_{n}=\frac{2}{7}$ and $c_{n}=\frac{1}{3}$. 
Remark 1. Since Karaca and Yildirim showed that the iteration (1.6) is better than the Mann, the Ishikawa and the Noor iteration under the same control conditions in Table (1) in [5] and since the iteration (1.8) is better than the iteration (1.7) ; from the example above, we see that the iteration (1.6) is also better than the Mann, the Ishikawa and the Noor iteration (see Table 1).

TABLE 1. Comparison of rates of convergence between the Mann, the Ishikawa, the Noor, the iteration (1.7) and the iteration (1.8) for the given function in Example 1.

\begin{tabular}{|c|c|c|c|c|c|}
\hline$n$ & Mann & Ishikawa & Noor & Iteration (1.7) & Iteration (1.8) \\
\hline 1 & 3.0000000000000 & 3.0000000000000 & 3.0000000000000 & 3.0000000000000 & 3.0000000000000 \\
\hline 2 & 2.5714285714286 & 2.3888439436791 & 2.4008746355685 & 1.7313063612876 & 1.5401673015252 \\
\hline 3 & 2.4174927113703 & 2.2254517072870 & 2.2376492818701 & 1.5181740350893 & 1.1412984225699 \\
\hline 4 & 2.3449473117980 & 2.1550012729794 & 2.1669386104705 & 1.4419390309085 & 1.0370942630072 \\
\hline 5 & 2.3036376203066 & 2.1162688700155 & 2.1279937754439 & 1.4035834760126 & 1.0098984194011 \\
\hline 6 & 2.2771611529634 & 2.0918680685218 & 2.1034379658412 & 1.3806435160226 & 1.0026876820299 \\
\hline 7 & 2.2588033724454 & 2.0751132884023 & 2.08656855584221 & 1.3654218100568 & 1.0007395163945 \\
\hline 8 & 2.2453478554976 & 2.0629069049125 & 2.0742749466098 & 1.3545983144137 & 1.0002053712816 \\
\hline 9 & 2.2350712664948 & 20205337 & 2.0649218163292 & 1.3465132450409 & 1.0000574007962 \\
\hline 10 & 2.2269702990746 & 2.0463236735674 & 2.057568 & 1.3402467219105 & 1.0000161162114 \\
\hline 11 & 2.2204223565279 & 2.0404368413529 & 371936686 & 5577363 & 1.0000045397692 \\
\hline 12 & 2.2150210906564 & 2.0355886384227 & 2.0467517462118 & 1.3311697883865 & 1.0000012819360 \\
\hline 13 & 2.2104902244470 & 2.0315267588978 & 2.0426584045758 & 1.3277785155870 & 1.0000003626680 \\
\hline 14 & 2.2066354643304 & 2.0280744244732 & 2.0391791535626 & 1.3249146769522 & 1.0000001027505 \\
\hline 15 & 2.2033162415763 & 2.0251041121328 & 2.0361855592762 & 1.3224642602428 & 1.0000000291448 \\
\hline 16 & 2.2004283710133 & 2.0225215278982 & 2.0335826431041 & 1.3203438702731 & 1.0000000082746 \\
\hline 17 & 2.1978930104902 & 2.02025 & 2.0312986612631 & 1072883 & 1.0000000023511 \\
\hline 18 & 56494058656 & 10914141 & 2.029 & 68583563639 & 1.0000000006684 \\
\hline 19 & 2.1936499906887 & 2.0164656045780 & 2.0274787359825 & 54086566764 & 1.0000000001901 \\
\hline 20 & 2.1918569955612 & 2.0148650125129 & 2.0258653933936 & 1.3141128814885 & 1.0000000000541 \\
\hline 21 & 2.1902400515356 & 2.01342202078 & & 7682783 & 1.0000000000154 \\
\hline 22 & 2.1887744636632 & 2.0121144533649 & 2.0230928598647 & 1.3118945144684 & 1.0000000000044 \\
\hline 23 & 2.1874399459628 & 2.0109241069485 & 2.0218929797399 & 1.3109377580364 & 1.0000000000013 \\
\hline 24 & 2.1862196801664 & 2.0098358997613 & 2.0207960445974 & 1.3100648253675 & 1.0000000000004 \\
\hline 25 & 2.1850996055759 & 2.0088372301401 & 2.0197893550185 & 1.3092651680701 & 1.0000000000001 \\
\hline 26 & 2.1840678764676 & 2.0079174869986 & 2.0188622173221 & 1.3085299356161 & 1.0000000000000 \\
\hline
\end{tabular}

We also give a graphic to compare the rates of convergence of the iterations mentioned in Example 1 visually. 


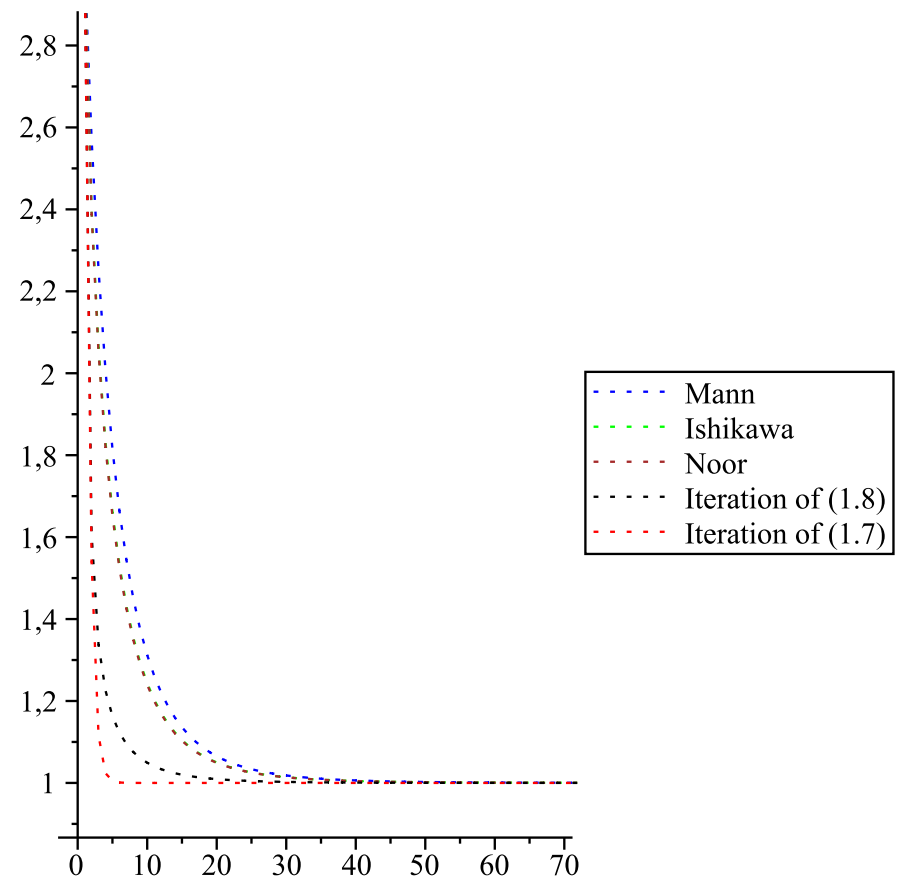

FIGURE 1. Behaviour of the iterations given in Example 1.

\section{REFERENCES}

[1] R. P. Agarwal, D. O' Regan, and D. R. Sahu, "Iterative construction of fixed points of nearly asymptotically nonexpansive mappings." J. Nonlinear Convex Anal., vol. 8, no. 1, pp. 61-79, 2007.

[2] D. Borwein and J. Borwein, "Approximating fixed points of nonexpansive mappings by a faster iteraiton process.” J. Math. Anal., vol. 157, pp. 112-126, 1991.

[3] P. Cholamjiyak and S. Baiya, "Convergence theorem convergence rate and convergence spped for continuous real functions." Filomat, vol. 30:2, pp. 505-513, 2016, doi: 10.2298/FIL1602505C.

[4] S. Ishikawa, "Fixed points by a new iteration method." Proc. Amer. Math. Soc., vol. 44, pp. 147150, 1974, doi: 10.1090/S0002-9939-1974-0336469-5.

[5] N. Kadioglu and I. Yildirim, "On the Rate of Convergence of Mann Ishikawa Noor and SP iterations for Continuous Functions on an Arbitrary Interval." Fixed Point Theory and Applications, vol. 2013, p. 124, 2013, doi: 10.1186/1687-1812-2013-124. 
[6] N. Karaca and I. Yildirim, "Approximating fixed points of nonexpansive mappings by a faster iteraiton process." J. Adv. Math. Stud. Vol., vol. 8, pp. 257-264, 2015.

[7] W. R. Mann, "Mean value methods in iteration." Proc. Amer. Math. Soc., vol. 4, pp. 506-510, 1953, doi: 10.1090/S0002-9939-1953-0054846-3.

[8] M. A. Noor, "New Approximation Schemes for General Variational Inequalities." J. Math. Anal. Appl., vol. 251, pp. 217-229, 2000, doi: 10.1006/jmaa.2000.7042.

[9] W. Phuengrattana and S. Suantai, "On the Rate of Convergence of Mann Ishikawa Noor and SP iterations for Continuous Functions on an Arbitrary Interval.” J. Math. Anal. Appl., vol. 235, pp. 3006-3014, 2011, doi: 10.1016/j.cam.2010.12.022.

[10] E. Picard, "Memoire sur la theorie des equation aux derivees partielles la methode des approximations successives." J. Math. Pures Appl., vol. 6, pp. 145-210, 1890.

[11] Y. Qing and L. Qihou, "The necessary and sufficient condition for the convergence of Ishikawa iteration on an arbitrary interval." J. Math. Anal. Appl., vol. 323, pp. 1383-1386, 2006, doi: 10.1016/j.jmaa.2005.11.058.

[12] B. E. Rhoades, "Comments on two fixed point iteration methods." Journal of Mathematical Analysis and Applications, vol. 56, pp. 741-750, 1976, doi: 10.1016/0022-247X(76)90038-X.

Authors' addresses

Osman Alagoz

Bilecik Seyh Edebali University, Department of Mathematics, 11000, Bilecik, Turkey

E-mail address: osman.alagoz@bilecik.edu.tr

Birol Gunduz

Erzincan University, Department of Mathematics, 24000 Erzincan, Turkey

E-mail address: birolgndz@gmail.com

Sezgin Akbulut

Ataturk University, Department of Mathematics, 25000, Erzurum, Turkey

E-mail address: sezginakbulut eatauni.edu.tr 